\title{
The Ambivalent Effect of Complexity on Firm Performance A Study of the Global Service Provider Industry
}

\author{
Larsen, Marcus M.; Manning, Stephan; Pedersen, Torben
}

Document Version

Accepted author manuscript

Published in:

Long Range Planning

DOI:

10.1016/j.Irp.2018.02.002

Publication date:

2019

\section{License \\ CC BY-NC-ND}

Citation for published version (APA):

Larsen, M. M., Manning, S., \& Pedersen, T. (2019). The Ambivalent Effect of Complexity on Firm Performance: A Study of the Global Service Provider Industry. Long Range Planning, 52(2), 221-235.

https://doi.org/10.1016/j.Irp.2018.02.002

Link to publication in CBS Research Portal

\section{General rights}

Copyright and moral rights for the publications made accessible in the public portal are retained by the authors and/or other copyright owners and it is a condition of accessing publications that users recognise and abide by the legal requirements associated with these rights.

Take down policy

If you believe that this document breaches copyright please contact us (research.lib@cbs.dk) providing details, and we will remove access to the work immediately and investigate your claim. 


\title{
The Ambivalent Effect of Complexity on Firm Performance: A Study of the Global Service Provider Industry
}

\author{
Marcus M. Larsen, Stephan Manning, and Torben Pedersen
}

Journal article (Accepted manuscript*)

\section{Please cite this article as:}

Larsen, M. M., Manning, S., \& Pedersen, T. (2019). The Ambivalent Effect of Complexity on Firm Performance:

A Study of the Global Service Provider Industry. Long Range Planning, 522), 221-235. DOI:

10.1016/j.Irp.2018.02.002

DOI: 10.1016/j.lrp.2018.02.002

* This version of the article has been accepted for publication and undergone full peer review but has not been through the copyediting, typesetting, pagination and proofreading process, which may lead to differences between this version and the publisher's final version AKA Version of Record.

Uploaded to CBS Research Portal: June २०19

(C) 2019. This manuscript version is made available under the CC-BY-NC-ND 4.0 license http://creativecommons.org/licenses/by-nc-nd/4.0/ 
THE AMBIVALENT EFFECT OF COMPLEXITY ON FIRM PERFORMANCE:

A STUDY OF THE GLOBAL SERVICE PROVIDER INDUSTRY

\author{
Marcus M. Larsen* \\ Copenhagen Business School \\ Department of Strategic Management and Globalization \\ Kilevej 14, $2^{\text {nd }}$ floor, 2000 Frederiksberg, Denmark \\ $\&$ \\ Department of Strategy and Entrepreneurship \\ BI Norwegian Business School \\ Nydalsveien 37 - 0484 Oslo - Norway \\ Tel: +45 38155628 / e-mail: $\underline{\text { mml.smg@cbs.dk }}$
}

\title{
Stephan Manning
}

University of Massachusetts Boston

College of Management

100 Morrissey Boulevard, Boston, MA 02125-3393, United States

Tel: +1617287 7736 / e-mail: stephan.manning@umb.edu

\section{Torben Pedersen}

Università Bocconi

Department of Management and Technology

Via Sarfatti, 25 Milano, Italy

Tel: +390258363535 / e-mail: torben.pedersen@unibocconi.it

Published in: Long Range Planning (2018), https://doi.org/10.1016/j.lrp.2018.02.002 


\title{
THE AMBIVALENT EFFECT OF COMPLEXITY ON FIRM PERFORMANCE: A STUDY OF THE GLOBAL SERVICE PROVIDER INDUSTRY
}

\begin{abstract}
Prior literature is ambivalent about whether organizational complexity has positive or negative effects on firm performance. Using rich data on global service providers, we explore this tension by disentangling performance consequences of different types of organizational complexity. We show that complexity arising from the coordination of different services and operations negatively influences profit margins through increased coordination costs, whereas complexity coming from the sophistication of particular services may positively influence margins through informational advantages. Our findings help better differentiate performance effects of organizational complexity and the role of core contingencies.
\end{abstract}

Keywords: Complexity, service provider industry, commoditization, client-specific investments. 


\section{INTRODUCTION}

Understanding the performance implications of organizational complexity remains a key concern in management research. In response to increasingly multifaceted and dynamic global business contexts, firms often build up internal organizational complexity to better match environmental demands (Dougherty, 2004; Garud et al., 2011; Niosi, 2011). Yet, the implications of such actions remain ambivalent. On the one hand, complexity may jeopardize the organizational ability to process information (Ethiraj and Levinthal, 2004; Tushman and Nadler, 1978), which in turn can increase the likelihood of decision errors and eventually lower firm performance (Levinthal, 1997). On the other hand, complexity may support capabilities that are difficult to monitor and imitate (Husted, 2007; Reed and DeFillippi, 1990; Rivkin, 2001), which in turn may promote rent appropriation and help firms develop a competitive advantage (Lippman and Rumelt, 1982; Powell et al., 2006).

In this article, we explore the ambivalent performance consequences of organizational complexity. While existing research has produced important insights on how complexity may either deteriorate or enhance firm performance, less is known about when the opposing effects emerge. Hence, the aim of this article is to differentiate specific performance contingencies of organizational complexity. In doing so, we follow a long tradition in organizational theory in defining complexity as a property of a system characterized by a large number of interdependent organizational tasks and operations (Simon, 1962; Porter and Siggelkow, 2008; Zhou, 2013). Moreover, rather than treating complexity as a single organizational construct, we emphasize that different types of organizational complexity may yield different performance effects. Following existing research (e.g., Larsen et al, 2013; Løwendahl and Revang, 1998; Siggelkow, 2001), we explore the different performance effects of configuration complexity, i.e., complexity arising 
from coordinating various organizational tasks and operations, and task complexity, i.e., complexity arising from coordinating needs within particular tasks.

Our empirical context are global service providers who provide a range from simple to sophisticated services from a number of locations to satisfy client demand (Manning et al., 2015), which makes this industry particularly suitable for our purpose. We argue that while both configuration and task complexity imply coordination costs, their performance implications are different. As for configuration complexity, coordination costs increase as providers coordinate a larger number of interdependent operations and locations (Rawley, 2010; Zhou, 2011). As such, this type of complexity has negative effects on firm performance. Task complexity, which is more specific to particular client services, also generates coordination costs. Yet, we argue that this type of complexity may positively influence profit margins. Specifically, we suggest that the coordinative specialization associated with task complexity promotes information asymmetry between providers and clients (Nayyar, 1993). Providers with a superior knowledge base are thus better able to shift or delegate a larger portion of coordination costs to the client. Thereby, suppliers are able to offset the coordination costs involved in performing particular tasks and appropriate higher economic rents. Finally, we also argue and show empirically that the magnitude of performance effects of complexity depend on the moderating effects of process commoditization and client-specific investment.

With this research, we make several important contributions. As firms build more complexity in response to changing environments and client needs, our results point to an important trade-off between managing coordination costs and meeting client expectations. Yet, performance effects differ depending on the level in the organization at which complexity and coordination costs arise. Thus, rather than treating organizational complexity as an aggregate 
construct (cf., Houchin and MacLean, 2005), we propose a more fine-grained understanding of complexity and its effects. Our findings not only help better understand the performance conditions in the increasingly important service provider industry, but also have important strategic implications for any firm confronted with managing complex operations.

\section{THEORY AND HYPOTHESES}

\section{Disentangling organizational complexity}

Much work has been devoted to investigating the consequences of organizational complexity. Beginning in the 1960s with the open-systems view of organizations, complexity has been a central construct in explaining the internal and external interconnectedness of organizations (cf., Anderson, 1999; Houchin and MacLean, 2005; Moldoveanu and Bauer, 2004). For example, in his seminal article on the architecture of complexity, Simon (1962: 468) describes a complex system as "one made up of a large number of parts that interact in a nonsimple way". In a similar manner, Thompson (1967) portrays a complex organization as a set of many interdependent tasks and argues that a central managerial challenge is to cope with its consequences. This view suggests that systems are complex when the different organizational components are growingly interdependent (e.g., Albert et al., 2015; Porter and Siggelkow, 2008; Simon, 1962). For example, an organization managing a number of different activities in a wide spread of countries can be regarded as more complex than a solely domestic organization dealing with only few activities.

Based on this view of complexity, a main consequence of complexity is its associated coordination costs (Galbraith, 1973; Thompson, 1967; Zhou, 2011). Coordination costs can be understood as the costs involved in establishing effective communication and decision-making among organizational members to complete work jointly, and to orchestrate operations across or 
within organizational boundaries (Gulati and Singh, 1998). Accordingly, an increasingly interdependent organization requires costly investments into appropriate mechanisms of communication to ensure efficient coordination. For example, in the late 2000s Cisco Systems invested heavily in sophisticated virtual conferencing and other communication technology to more effectively coordinate its globally distributed operational structure, including two headquarters in San Jose and Bangalore, and to facilitate decision-making across locations. Similarly, Manning et al. (2013) describe in their study of a German automotive supplier how the costly investment of a dozen of engineering support centers around the world created the demand for new 'interface management' roles and staff positions to ensure quality control. Both examples stress how organizational complexity increases coordination costs, which, in turn, puts pressure on the financial performance of organizations. In addition, the information processing demand caused by complex systems may spur organizational inertia (Hannan and Freeman, 1984; Tushman and Nadler, 1978), and undermine precision in decision-making, thus further challenging firm performance (Larsen et al., 2013; Levinthal, 1997).

However, instead of seeing complexity as a comprehensive, unanimous source of coordination costs, we emphasize that different types of complexity exist within organizational systems simultaneously and that different types may generate different performance effects (e.g., complexity in organizations, tasks, projects, etc.). For example, Siggelkow (2001) points out in his study of the fashion company Liz Claiborne that organizational complexity arises from interdependencies both within and between major internal value chain activities (e.g., the product portfolio, marketing, production, etc.). Studying hidden costs in offshoring, Larsen et al. (2013) similarly distinguish between complexity within tasks (task complexity) and between tasks and operations (configuration complexity). Whereas the former drives cost underestimation 
especially when tasks are outsourced, the latter increases hidden costs particularly when operations are coordinated internally. In addition, prior studies suggest that coordination challenges of configuration and task complexity may differ. For example, Manning et al. (2013) emphasize in their study that the effective conduct of specific engineering tests (task complexity) may require interface management, but that securing quality control across test centers (configuration complexity) requires continuous learning and exchange of good practice among interface managers. These studies therefore suggest that a distinction between configuration and task complexity may be useful to disentangle performance effects and contingencies of organizational complexity.

Along these lines, we define configuration complexity as a property of interdependencies connecting the operations of an organization (Blau and McKinley, 1979; Damanpour, 1996). More specifically, configuration complexity is related to the multiplicity of and linkages between locations and operations within an organization. It arises from various coordination needs, including strategic alignment and resource allocation, across at times concurrent operations. As such, a firm operating a number of manufacturing plants across locations can be characterized as more complex than a firm operating a single facility at a single location.

Task complexity concerns the complexity inherent in individual organizational tasks (e.g., Campbell, 1988; Wood, 1986; Hærem et al., 2015) and relates to the "a priori determinability of, or uncertainty about, task outcomes, process, and information requirements" (Byström and Järvelin, 1995: 194). As recently emphasized by Weigelt and Miller (2013: 1413), task complexity is reflected by the number and interdependencies of specialized knowledge exchanges between actors required for successful task implementation. Accordingly, task complexity typically arises from the need to coordinate task completion with the expectations of 
those 'requesting' a task. In this study, we thus focus specifically on tasks requested from other internal or external clients of the organization.

\section{The performance effects of configuration and task complexity}

In the following, we develop hypotheses on the performance effects of the two types of complexity. As firm performance is inherently multifaceted and thus difficult to conceptualize and interpret (Miller et al., 2013), we focus explicitly on the profit margins that suppliers can obtain from their operations vis-à-vis their clients. Profit margins have become a key concern for suppliers as products and services have become more commoditized and competition for client projects has increased (Davenport, 2005). Specifically, we argue that coordination costs arise from both types of complexities, but that their impacts on performance may differ. Task complexity in particular may induce information asymmetries vis-à-vis clients and thus create opportunities for shifting or delegating coordination costs and thus appropriating economic rents. We thus expect opposing effects on the profit margin of a firm's operations.

First, when firms take configurational actions such as diversifying their operations across functions and geographies, they must engage in the costly act of coordinating interdependencies connecting these different operations. This effect has been well documented in prior studies. For example, Zhou (2011) argues that the potential synergistic benefits of related diversification among U.S. equipment manufacturers may be offset by the added complexity and costs of managing interdependencies between different business lines. Rawley (2010) argues that diversifying from taxicab to limousine services creates complexities and coordination costs that offset economies of scope and increase organizational rigidity. In other words, as firms increase configuration complexity, they need to invest resources in mechanisms to accommodate for new coordination requirements (Srikanth and Puranam, 2011). Thus, while strategies like 
diversification can create long-term benefits such as synergies and new market opportunities, firms need to invest in additional coordination efforts. Therefore, higher configuration complexity should in the intermediate term lead to increased coordination costs, which, ceteris paribus, negatively influence the margins that firms can appropriate from their operations (Larsen et al., 2013; Rawley, 2010; Zhou, 2011).

As for task complexity, we emphasize that the often vague and ambiguous requirements associated with the completion of complex tasks (e.g., Campbell, 1988; Wood, 1986) allow task providers to delegate part of the coordination costs to clients. Complex tasks typically require specialized, and often intangible, knowledge, skill sets and the use of advanced technologies. A consequence of this, however, is the generation of 'zones of uncertainty' (Crozier and Friedberg, 1980) and information asymmetries that task providers can exploit vis-à-vis their clients (Nayyar, 1993). For example, in order to perform a complex task to client satisfaction, providers may ask clients to invest additional time and resources in specifying the deliverable and/or in adding their own personnel to service delivery teams, which generates extra costs on the client side. The more complex the task the less able the client will be to monitor what resources the service provider utilizes (vs. the client) in provision of the task, and is consequently restrained from controlling strategizing behavior of the provider.

Providers may thus exploit their specialized knowledge involved in the performance of tasks and related sub-tasks that is unattainable by the client. Moreover, as task complexity often encompasses multiple actors (Hærem et al, 2015) and unfolds through processes and activities with the involvement of partners, the costs of coordinating within-task interdependencies are typically distributed heterogeneously across various actors. Accordingly, we expect that those 
actors controlling critical information are in a better position to delegate coordination costs to those suffering from information asymmetry.

Complex consulting projects whose value creation is typically not transparent to clients provides a good example of this mechanism (Sturdy, 1997). Consulting firms often co-determine the composition of project teams with clients and specify what information and services clients need to provide in order for projects to succeed. In particular, complex projects give consulting firms the opportunity to delegate parts of the costs of coordination to clients . As such, the providers with superior knowledge on the processes of the tasks are in a better position to delegate the coordination costs stemming from the projects to the clients, and hence appropriating economic rents from information asymmetries (e.g., Nayyar, 1993).

Taken together, we hypothesize that configuration and task complexity differ in their performance effects, mainly due to differences in the ability to 'distribute' coordination costs among parties. Whereas firms largely bear the coordination costs from configuration complexity, they can partially delegate coordination costs at the task level. We hypothesize:

Hypothesis 1a: Configuration complexity is negatively related to the profit margins of a firm's operations.

Hypothesis 1b: Task complexity is positively related to profit margins of a firm's operations.

\section{The moderating effects of commoditization and client-specific investments}

While performance effects of organizational complexity are ambivalent, they are also contingent upon key moderating mechanisms. Following the logic extrapolated above, measures that reduce coordination costs should positively influence the performance effects of configuration complexity, while measures that reduce information asymmetry should negatively influence the 
performance effects of task complexity. To explore this, we focus on the moderating effects of process commoditization and client-specific investments.

First, we argue that process commoditization affects the performance effects of configurational complexity. Specifically, the degree to which tasks and processes are standardized and modularized has important implications for keeping the coordination costs derived from configuration complexity at bay (Davenport, 2005; Sako, 2006; Tanriverdi et al., 2007). Standardization may ease comparative measures of performance and make information less 'sticky' (von Hippel, 1994; Kumar et al., 2009). Standardization also facilitates personnel exchanges, staff hiring and training, and supports the overall operational flexibility across a growing number of locations and service operation (Manning et al., 2015).

Moreover, commoditization is based on the principle of process modularity which describes the degree to which processes can be broken up into modular, semi-independent subprocesses, and which complements potential coordination needs arising from increasing diversity of operations and distribution of locations (Davenport, 2005; Simon, 2002). In a highly dispersed system, being able to perform sub-processes semi-independently in different locations not only generates specialization and efficiency advantages, but also lessens the need for costly coordination. For example, Manning et al. (2015) show how global service providers choose to set up networks of service delivery hubs across the world particularly for highly commoditized services, such as IT and tech support, facilitated by the reduced need for communication between locations. By keeping coordination costs low, providers can re-direct resources to various sources of revenue generation, such as client acquisition. In other words, while setting up global networks of service operations does increase configurational complexity for providers, process 
commoditization reduces the need for communication and coordination, and mitigates negative effects complexity might otherwise have on performance.

Therefore, a high degree of process commoditization offers a mechanism to reduce coordination costs, and should accordingly minimize the negative consequences of configuration complexity on profit margins (as hypothesized in H1a):

Hypothesis 2a: The negative association between configuration complexity and profit margins is positively moderated by the degree of process commoditization.

As for task complexity, we argue that client-specific investments have a particularly strong moderating effect. Above we argued that information asymmetry allows firms to appropriate higher economic rents from performing complex tasks through the delegation of coordination costs. However, information asymmetries may be reduced through client-specific investments - investments into tasks, processes and technologies supporting operations that make these more specific to client operations and requirements (e.g., Williamson, 1975). We argue that such investments lower the positive performance effects of task complexity. As firms align their processes and technologies with their clients-for example, by using the same process specifications, by training staff according to client-specific requirements, or by applying the same performance evaluation criteria-the information asymmetry weakens as it becomes easier for clients to monitor and evaluate processes and performance. Even if clients are unfamiliar with sub-processes involved in performing particular tasks, a high level of process and client integration due to client-specific investments generates more frequent and immediate feedback (Luo et al., 2013), thus lowering the ability of providers to generate margins.

However, client-specific investments also have a more direct effect on the way in which coordination costs are distributed. A large part of the coordination costs arising from task 
complexity occur in form of task-specific investments. The more providers are able to make clients invest into the successful completion of tasks, the more are they able to delegate costs of coordination. Likewise, the more clients are able to make providers invest, i.e. make clientspecific investments, the more do providers need to bear coordination costs. To what extent each party needs to make specific investments may be a result of each party's bargaining power and other factors. For example, leading original equipment manufacturers in the automotive sector typically have the power to make their suppliers invest into particular client-specific systems and standards to facilitate task delivery. This will increase coordination costs for suppliers, while at the same time reducing information asymmetries vis-à-vis clients, which, in combination, has a negatively impact on suppliers' margins. We thus hypothesize:

Hypothesis 2b: The positive association between task complexity and profit margins is negatively moderated by the degree of client-specific investments.

\section{METHODS}

\section{Research context: The global service provider industry}

We investigate how configuration and task complexity affect performance in a relatively new, yet fast growing and increasingly important industry: the global service provider industry. Facilitated by increasing digitalization and commoditization of business processes, client firms across industries, from the U.S. and Western Europe in particular, increasingly outsource business process tasks (such as IT infrastructure, payroll, tech support, inbound and outbound calls, but also software development and testing, engineering support and product design) to specialized service providers operating across the world.

We find this context particularly apt for our research purpose. Increasing client demand for outsourcing services has been paralleled by a sophistication of the supply of various service 
tasks and the development of client-serving capabilities (Athreye, 2005; Ethiraj et al., 2005). For example, several large providers headquartered in India have developed so-called global delivery models involving distributed teams at both onshore (client-side) and offshore facilities, collaborating across time zones (Manning et al, 2015). Yet, this increasing ability to provide numerous services globally through distributed delivery structures entails interdependencies across locations and as such increases the configuration complexity of service operations. Similar to client firms with large-scale internal offshore operations, full-service providers are challenged by increasing coordination and overhead costs affecting not only cost savings for clients but their own margins as well.

Moreover, the range of tasks - from routine and standardized, to complex and knowledge intensive - has also increased. Whereas prior to 2000, most service providers focused on commoditized IT and software tasks (e.g., Dossani and Kenney, 2007; Ethiraj et al., 2005), over time providers have not only increased the spectrum of more standardized task and service offerings (e.g., Jones 2000; Sako, 2006), but also added more complex, often knowledgeintensive services, such as engineering, design, and analytical services (Lewin et al., 2009).

\section{Data collection}

We test our hypotheses based on service provider survey data collected by the international Offshoring Research Network (ORN). The ORN is an international research initiative launched in 2004 at Duke University, which involves partner universities in Europe and Asia. A number of papers have been published based on the ORN data (e.g., Elia et al., 2014; Larsen et al., 2013; Lewin et al, 2009; Manning et al., 2008). Noticeably, the majority of these papers have applied the ORN client data. By contrast, we draw primarily on the ORN service provider data which is collected both on the firm level and on the service level. Survey items and results of initial 
survey rounds were regularly presented through workshops and webinars to consultants, industry experts and practitioners, and feedback from these interactions has been integrated into the survey design. The survey has been taken online where respondents reach the survey website through external links or email invitations. Once registered and approved by the ORN survey team, respondents are added to the database. In some cases, in particular large firm respondents would submit the survey uncompleted, resulting in a number of missing variables, despite reminders to answer all questions.

\section{Sample}

Our database contains data from 755 providers based in different countries and regions. While most providers in the sample are major players, such as Accenture, Infosys, TCS, IBM Global Services, Genpact, Tata Consulting, our sample also includes small and midsized firms. It should be noted, however, that only 191 providers provided sufficiently detailed information resulting in a usable sample of 432 data points (as each provider on average has responded for 2.3 classes of service). Our sample includes providers headquartered all over the world offering different classes of services to global clients. The three most important provider headquarter locations are: USA (33.9\%), India (12.7\%), and China (11.5\%). The three most important classes of services are: IT (20.6\%), Software (17.7\%), and Call Centers (9.2\%).

We examined the risk of nonresponse bias by comparing selective sample distributions of the completed responses sample with the missing responses sample in terms of firm size, headquarter location, and distribution of tasks specified. As for headquarter and service distribution, differences between subsamples are insignificant. This is not the case for size, however. The completed responses sample is significantly biased towards small firms with less than 500 employees $(60 \%)$ and midsize firms with more than 500 but less than 10,000 employees 
(32\%) versus large firms with more than 10,000 employees (8\%). By comparison, the missing responses sample has a distribution of $25 \%$ large, $40 \%$ midsize and $35 \%$ small firms. The main reason for this difference is the difficulties many large firm respondents encounter when taking the detailed multi-level questionnaire with arrays of questions for each type of service. Although various methods exist to replace missing values, we decided to only use actual responses. We followed the rationale that respondents giving information on all items are likely to be more accurate with any particular data item than respondents giving only partial information. While the resulting exclusion of a number of larger firms might be a limitation, one positive side effect of the resulting bias towards smaller firms is that the initial overrepresentation of large firms in the total sample is corrected. This overrepresentation was initially due to the strategy of including most major service providers. In practice, however, midsize and smaller firms are the vast majority of providers which is reflected in the completed responses sample.

Moreover, common method bias is an obvious limitation of survey based measures. To address this issue, we performed a number of statistical analyses to assess the severity of this bias. The Harman's one-factor test on the variables indicated that common methods bias was not an issue as multiple factors were detected and the variance did not merely stem from the first factors (Podsakoff and Organ, 1986). In fact, the 29 variables included in the model (all listed in Table 1) form several factors with an eigenvalue $>1$ and with the two major factors only explaining $9 \%$ and $8 \%$, respectively. In addition, we ran a confirmatory factor analysis where all items loaded on the same factor (a Single Factor Model). The assumption is that the existence of a single factor that is the common denominator across all items reflects the presence of a common method bias (Podsakoff et. al, 2003). However, in our case the goodness-of-fit statistics is highly unsatisfactory for the Single Factor Model capturing the common method bias, which 
indicates that we do not have a major problem of common method bias in the data. Furthermore, we conducted an analysis involving marker variables (Lindell and Whitney, 2001). Although these marker variables in some cases have separate explanatory power, they do not remove the significance of our key variables. Finally, the questionnaire of the service provider survey consisted of different scales (some of which were reversed). This, in combination with the fact that our results are based on complex estimations that involve multiple independent variables and interaction terms, makes it highly unlikely that the results of such models emerge solely as a result of common method bias (Siemsen et al, 2010).

\section{Measures}

The basic unit of analysis is the class of service (e.g., "Call center" or "Legal services") offered by the service provider. A complete list of all the 12 classes of service included in this study is provided in the correlation matrix - Table 1 - as variables 14-25). Within each class of service,

providers typically perform multiple tasks. For example, as part of 'finance and accounting services', providers may perform accounts payable and receivable, cash management, credit card operations, fixed asset accounting, etc. Configuration complexity thus relates to the complexity of operations and locations supporting a service class, whereas task complexity concerns the average complexity of the actual tasks provided within a service class. All variables are measured at the level of the class of service.

\section{Dependent variable}

Profit margins is a measure of the average return for offering services within each class of service that a service provider offers. This implies that profit margins are measured at the level of each class of service rather than across services. Interestingly, many prior studies on global services outsourcing have focused on client performance, in terms of cost savings, service 
quality, data security and reliability (e.g., Ellram et al., 2008; Luo et al., 2013), whereas provider performance has been somewhat neglected (but see e.g., Lahiri and Kedia, 2009; Lahiri et al., 2012). From a provider's perspective, in particular profit margins have become a key concern, as services have become more commoditized and competition for client projects has increased. Thus, we focus explicitly on provider's margins as a primary performance indicator. Since no objective measure is available in our data for profit margins at the service level, the information for this variable was acquired as a self-reported measure. More specifically, respondents were asked to indicate "for each class of services that your company provides, what is the average achieved margin (in \%) on deals (once deals have been implemented)?" Respondents were asked to indicate the average margin in percentage (i.e., revenue - costs / revenue $* 100 \%$ ) over deals in the same class in order to even out fluctuations on individual deals. The margin can vary from a negative value if costs exceed revenue to almost $100 \%$ if costs are negligible compared to revenue. The average profit margin across the 446 observations is $26 \%$ with significant variation as the standard deviation is $18.6 \%$ (see Table 1 ).

\section{Independent variables}

Configuration complexity is a constructed measure that seeks to capture the complexity deriving from maintaining often multiple, distributed operations and related interdependencies within a particular service class. Following Larsen et al. (2013), we measure configuration complexity through three distinct items: the number of tasks performed within a particular service class, the dispersion of service delivery locations, and the number of employees in the given service class (see also Blau and McKinley, 1979; Damanpour, 1996). Thus, we created a variable that allows us to proxy the complexity of the entire organizational set-up around the provision of particular types of services, rather than the complexity residing within the completion of particular tasks. 
We assume that a service provider conducting a multiple tasks within a particular class of service from multiple locations with several employees is more likely to engage in costly coordination than a service provider performing only one or two services within the same class from a few locations with few employees. Operationally, our variable is measured as the product of number of tasks a firm performs within a service class; the number of locations a firm conducts services from; and the logarithm of the number of staff employed (in thousands) in the service class. All three items were standardized before multiplying them in order to give them equal weight in the composite measure. The mean of this variable is 0.1 (see Table 1), but with a substantial variation given the standard deviation of 0.36 .

Task complexity is a single-item measure capturing the complexity of performing tasks within a particular class of service. The respondents were asked about the characteristics of tasks within each class of service provided by the company. On a scale from 1 to 5 , where 1 is "very low", 3 is "average" and 5 is "very high" respondents were asked the following exact question: "For each class of services that your company provides, please indicate the degree to which the tasks involved have the following characteristics: highly complex." The purpose of including this measure is to capture the complexity inherent in performing individual tasks for particular clients, rather than the complexity of coordinating the entire set-up of globally dispersed operations and teams within a service class (e.g., Campbell, 1988; Larsen et al, 2013). We draw on previous research in assuming that a high degree of task complexity equals tasks with more internal interdependencies (Murmann, 1994; Weigelt and Miller, 2013). For example, Weigelt and Miller (2013: 1413) emphasize that "Complex tasks build on a greater number of specialized knowledge sets and require more interdependency and knowledge exchange between actors for 
their execution than do simpler tasks." Descriptive statistics on this variable (Table 1) show that the mean is 3.6 which is well above the median (of 3) on the 5-point scale.

\section{Moderating variables}

Process commoditization is a single-item reflective measure capturing the degree to which the operation of a particular class of service has become highly commoditized, in terms of the standardization and modularity of tasks and processes within that service class. For example, highly commoditized types of services are based on process standards that are widely shared in the industry. Respondents were asked "for each class of services that your company provides, how commoditized has this service become?" and they indicated this on a 5-point scale (1=very low and $5=$ very high). The mean of the variable is 3.1 (Table 1), but with some variation given the standard deviation of 1.04 .

Client-specific investment is a measure of the extent to which the provider has to make investments before providing services that are specific to a particular client (and of less value for other clients). Respondents were asked "for each class of services that your company provides, to what extent does your company have to make client-specific investments?" Specifically, we focus on an item which asked respondents to indicate on a 5 -point scale $(1=$ not at all and $5=$ to a great extent) to what extent a class of service requires "client specific investments in training". The mean of the variable is 3.3 (Table 1), which is above the median of the 5-point scale. Notably, the survey also asks for client-specific investments in software and infrastructure. However, we focus here on training since our main interest is in capturing how clients counterbalance potential information asymmetries. As clients participate in providing task-specific knowledge to provider staff through training, the information asymmetries evaporate. For 
robustness checks, however, we also used combined measures for client-specific investments leading to qualitatively similar results.

\section{Control variables}

To further capture variance related to main variables of interest, we include a number of control variables. First, the years of provider experience with a particular service class and the total number of classes of services offered by the service provider are taken as proxies for the competencies and resources that the provider has accumulated over the years which is expected to have a positive effect on profit margins. Specifically, we assume in line with previous studies that global sourcing experience allows both clients and providers to develop the capacity to better manage and drive down the costs of a complex, globally dispersed set-up of operations (e.g., Massini et al., 2010). Thus, experienced service providers can be expected to generate higher margins than inexperienced providers. The average number of years of experience is 9.17 years, but with a span from 0 years to 85 years of experience, while the number of different classes of services offered varies from 1 to 10 with an average of 3.75 .

Second, we control for different aspects of the client relationship. Duration of deals (the average number of months that deals last for a given class of service) is controlled for as profit margins might decrease as clients learn to better anticipate costs but also capitalize on the willingness of providers to negotiate longer deals for discount rates. As shown in Table 1, the average is 2.26 while the span is from 0 to 37 months. Similarly, it is expected that the scope for information asymmetry diminishes in long-lasting relationships as clients acquire more knowledge on the involved tasks and their costs. Respondents were asked to provide the percentage of relationships that lasted $<1$ year, 1-2 years, 2-4 years, 5-6 years, 7-9 years and $>=$ 10 years, respectively. We have collapsed this information into the share of relationships lasting 
5 years or more (on average, this is the case for $35 \%$ of the relationships; standard deviation $32.5 \%$ - we controlled for other cut-off points and found similar results). Specification of contracts is also controlled for as the rent appropriation by the provider might be explained by loose and ill-specified contracts that similarly provide scope for strategizing behavior by the provider. Therefore, we expect profit margins to be negatively related to the level of contract specification. Respondents were asked for each class of service to indicate on a 5-point scale (1=strongly disagree and $5=$ strongly agree) whether deals are characterized by "highly specified contracts". The average value obtained is 3.3 with a standard deviation of 1.03 . Finally, we included a dummy variable on whether providers use subcontractors (1 - uses subcontractors; 0 - no subcontractors) for a particular service class as this might further increase coordination costs but also increase information asymmetry (the mean value is 0.25 with a standard deviation of 0.43$)$.

Third, we included two variables on the external environment that may also affect the profit opportunities in the particular service area: competition and innovation. We control for the level of competition for client deals in the specific service area since the profit margins might be a reflection of the lack of competition. Competition is calculated as the ratio of demand over supply in the specific service area; i.e., the number of outsourcing projects in a specific service area across the client population is divided by the number of providers offering this type of service. The number of outsourcing projects across the client population is collected from the ORN-client data, while the number of providers offering respective services is gathered in the ORN-provider data. Importantly, the ORN client survey captures, for each client firm, the total number of outsourcing projects in each category, rather than just whether or not a particular client has outsourced a particular task. This allows for a more nuanced demand measure. 
Compatibility between these two data sets is ensured by the same codification of classes of services. The average is 56.3 with a standard deviation of 27.7. Also the level of needed innovation in the service area might affect profit opportunities as more innovation on the provider side will foster information asymmetry and weaken the position of the client in relation to the provider (Dougherty, 2004). The innovation needed is captured by asking respondents to rate the following driver for clients to engage in the relationships on a scale from 1 to 5 : "Enhance capacity for innovation" (the average is 3.2 and the standard deviation is 1.1).

Finally, to capture variation of profit margins coming from specific properties of each class of service, we controlled for the type of services by using "other services" as a baseline and by including 12 dummy variables (one for each of the remaining classes of service), since the level of profit margins might also vary with the class of service. Similarly, we controlled for the location of the headquarters of the service providers by including 4 dummies (Asia, Europe, Latin America and North America) and using the rest of the world as the baseline. Here, the assumption is that being headquartered closer to major clients, e.g., in Europe or North America, may positively affect profit margins.

\section{RESULTS}

The correlation matrix is shown in Table 1 . None of the independent variables have correlations that indicate problems of multi-collinearity, as all of the correlations among the independent variables are below the commonly accepted threshold of 0.4. The only exception is the correlation between the dummies of headquarters in North America and Asia of 0.44, which follows naturally from the way the dummies are constructed. The correlation matrix also indicates that task complexity is high for $\mathrm{R} \& \mathrm{D}$ services, knowledge/analytical services and software development while it is low for call centers and HR services. This is very much in line 
with our expectations of knowledge-based activities being high on this scale, while standardized activities are low. As for configuration complexity, call center operations and finance/accounting-services correlate positively with this type of complexity, whereas procurement and product design show negative correlations. The potential multi-collinearity is further investigated by including VIF-values in the tested non-interaction models and as shown in Table 2 none of the VIF-values exceed the usual threshold of 6 (the only exception is the variable competition; however, as this variable is constructed within the different areas of services that are also controlled for, this is not unexpected).

\section{***Insert Table 1 here $* * *$}

Our unit of analysis is the individual service area. However, since some of the observations belong to the same firm (on average each firm provided information for 2.3 service areas) the assumption of independence among the observations is violated and we cannot run ordinary regression models. Instead, we ran a Hierarchical Linear Model (HLM) where we rule out firm interdependence as a random firm effect. More specifically, we ran HLMs with random intercepts at level 1 (the firm level) and fixed effects for all other variables at level 2 (the level of the service area). HLMs are particularly suitable given the nested structure of our data, the character of our dependent variable and the proposed relationships. Several alternative models have been tested, like ordinary regression models with firm fixed effects; however, results are qualitatively similar, but with weaker explanatory power. We examined residual plots and normal probability plots of the residuals for the tested models. To ease the interpretation of the HLM coefficients, we grand mean centered the independent variables (Hofmann and Gavin, 1998). The centering of the variables is also an advantage when conducting interaction effects as both interaction terms are centered on zero. In addition, we went one step further by 
standardizing all variables (mean=0 and std. dev.=1), but got very similar results, so we present the results for the centered variables. Since endogeneity might be a concern with some of the included variables, such as profit margin and complexity, we ran a number of Hausman tests (e.g., the endogeneity between profit margin and commoditization, task complexity and commoditization, task complexity and configuration complexity), but none indicated a significant problem of endogeneity.

Model 1 is our baseline model that only includes our control variables. In Model 2 and 3 we add separately the main effects of task complexity (Model 2) and configuration complexity (Model 3). Model 4 includes the main effects of our four hypothesized variables: configuration complexity, task complexity, process commoditization and client-specific investments. Finally, in Model 5, which is our full model, we add the two interaction effects between configuration complexity and commoditization, and between task complexity and client-specific investments. The results are presented in Table 2 with the coefficients, significance level, standard errors (in parentheses) and VIF-values (in italics) for each parameter.

$$
\text { ***Insert Table } 2 \text { here } * * *
$$

Model 1 indicates that none of the control variables is significant in explaining profit margin. Only the firm (level 1 intercept) has a significant effect on profit margins in Model 1, which indicates that a significant part of the variation in profit margins (for each service class) can be explained at the firm level. However, since our focus is on exploring the effect of complexity on performance at the level of the service class, we control out the firm-level effect without further investigating the nature of this firm-level effect. When separately adding the complexity variables in Models 2 and 3, only task complexity turned out to have a significant main effect (in Model 2), while configuration complexity is insignificant (Model 3). We also 
tested for non-linear relationships by separately adding the second order effects and the product of task complexity and configuration complexity, but all these effects turned out insignificant.

In Model 4, which includes the main effect of all our hypothesized variables, both task complexity and configuration complexity turn out significant, and with opposite signs as expected. Configuration complexity affects profit margins negatively $(\beta=-0.10, \mathrm{p}<0.05)$, while task complexity positively affects providers' profit margin $(\beta=2.64, \mathrm{p}<0.001)$ - as proposed in Hypotheses 1a and 1b. The full model is specified as Model 5, including the two interaction effects. This model also presents a significant improvement compared to Models 1 and 4 . The 2 log likelihood value is 3320.5 which is the best (lowest) of the presented models. It is noticeable that both interaction effects become significant as expected, while all other coefficients are relatively similar. The interaction effect between configuration complexity and process commoditization is significant and positive $(\beta=0.69, \mathrm{p}<0.01)$. This implies that the negative effect of configuration complexity on profit margins is reduced when the services are increasingly commoditized. Therefore, Hypothesis $2 \mathrm{a}$ can be supported. The interaction effect between task complexity and client-specific investment has the expected negative sign $(\beta=-0.25$, $\mathrm{p}<0.05)$, and is significant at the 5\%-level. This means that Hypothesis $2 \mathrm{~b}$ can also be supported.

***Insert Figures 1 and 2 here $* * *$

Since the sum of direct and indirect effects of the four variables included in the interaction effects is difficult to interpret, it is customary to draw the relationship in a graph as shown in Figure 1 and 2 (Aiken and West, 1991). Figures 1 and 2 are based on the coefficients of Model 5, and show the combined effect of the four variables that form the two interaction effects. The figures emphasize the moderating role of commoditization and client-specific 
investments, respectively. Figure 1 indicates that profit margins are highest when configuration complexity is low. When configuration complexity is high, profit margins are generally dropping, but they drop much more in case of low degree of commoditization. This indicates that degree of commoditization has performance implications in particular when configuration complexity is high. In turn, Figure 2 shows that profit margins are lowest when task complexity is low. When task complexity is high, profit margins rise slightly when providers need to make high levels of client-specific investments. However, they rise much more when providers do not need to make substantial client-specific investments. This implies that client-specific investments affect performance in particular in case of high task complexity.

To further interpret these results, we conducted simple slope tests for both interactions, as presented in Table 3 and Table 4. In the simple slope tests we vary our moderating variables from two standard deviations below the mean (-2 SD) to two standard deviations above the mean (+2 SD) in order to tease out the moderating effect. In Table 3 where configuration complexity is moderated by commoditization the gradient is negative in the whole window indicating that configuration complexity has a general negative effect on performance. However, the gradient becomes even more negative and significant the lower the level of commoditization. Contrary, in Table 4 the gradient is positive irrespective of the value of the moderator (client-specific investments), signifying the general positive performance effects of task complexity. However, this becomes weaker (lower gradient) when the level of client-specific investments increases.

$$
\text { ***Insert Tables } 3 \text { and } 4 \text { here } * * *
$$

Finally, we note that two of our control variables are significantly related to profit margins: competition $(\beta=-0.20, \mathrm{p}<0.01)$ and the use of subcontractors $(\beta=3.59, \mathrm{p}<0.05)$. While the negative effect of competition is expected, the positive effect of the use of 
subcontractors offers is less evident. On the one side, the use of subcontractors should entail additional coordination costs with fewer opportunities to appropriate additional rents. On the other side, the use of subcontractors may also suggest that providers themselves specialize in fewer areas of expertise, and are hence better positioned to extrapolate additional profit from those activities. We encourage future research to explore this issue further.

\section{Additional robustness tests}

We conducted a number of robustness checks to verify that our models are an unbiased account of our data. First, we ran models with alternative specifications of the interaction effects by interacting with client-specific investments with configuration complexity and commoditization with task complexity. However, regardless of whether these interaction effects were tested alone or in addition to other interaction effects, none of the models turned out to be significant. Accordingly, none of these alternative models was superior to our existing models. Second, we tested for a potential joint (interaction) effect of configuration complexity and task complexity on profit margins. This interaction effect between our two types of complexity turned out insignificant $(\beta=-0.003, \mathrm{p}=0.35)$. Together with the low correlation among them (of 0.03$)$, our results indicate that they are rather distinct types of complexity which affect profit margins differently. Third, we tested for non-linear effects of both our two complexity variables and our two moderators, but did not find any significant non-linear specifications of these variables. Finally, we did run our models while excluding the larger firms in our sample. When excluding all firms with more than 10,000 employees all our hypothesized relationships remained significant. However, when further excluding firms with more than 5,000 employees almost 100 observations are omitted and some of our results (specifically the interaction between task complexity and client-specific investments) become insignificant. 


\section{DISCUSSION AND CONCLUSION}

According to Reed and DeFillippi (1990: 91), "Complexity results from the relationship between skills, and between skills and assets. To suggest that complexity itself is a direct source of advantage would be misleading. However, the way in which the firm combines its skills and resources can be a source of advantage." In this article, we have focused on the specific contingencies that can explain firm performance as a result of increasing complexity. Much management research has tended to treat complexity as a one-dimensional construct associated with the level of interdependency between elements of a system - which may lead to negative consequences such as inefficiencies, inertia and lack of response capacity (Park and Ungson, 2001; Robson et al., 2008), but also potentially generate sources of competitive advantages and revenue generation (Lippman and Rumelt, 1982; Nayyar, 1993). Yet, the effects of complexity on performance often remain ambivalent (Houchin and MacLean, 2005).

To get a clearer understanding, we distinguished here between task and configuration complexity and their specific effects on firm performance. We argue and show empirically that configuration complexity negatively affects profit margins, whereas task complexity has a positive effect. Coordination costs are at the core of understanding these different effects. While the emergence of coordination costs is well-understood in the literature (Galbraith, 1973; Thompson, 1967; Zhou, 2011), we add to this debate that the degree to which focal firms need to 'bear' such costs may depend on where complexity arises and how it is moderated by other factors. In the case of configuration complexity, which arises from expanding operations across locations, firms typically need to bear the full costs of coordinating these operations. Such costs may be reduced, however, when processes are highly commoditized. By comparison, in the case of task complexity, costs of coordination are distributed among those parties involved in either 
requesting or performing a particular task. High task complexity gives firms the opportunity to exploit information asymmetries and 'zones of uncertainty' (Crozier and Friedberg, 1980) vis-àvis clients and delegate task-specific investments and other coordination costs to clients, which may positively affect margins. Likewise, under certain conditions, such as high bargaining power of clients, providers may need to make client-specific investments, thus bearing a higher share of coordination costs. This will lower the otherwise positive performance effects of task complexity. Under all circumstances, future research should take into account the fact that different types of complexity may produce opposing performance effects.

Obviously, we are not ruling out the alternative performance effects of configuration and task complexity. For example, firms deciding to diversify-i.e., increase their configuration complexity - can achieve strong scope economies by replicating old routines across new units (Teece, 1980). Equally, it is well established that task complexity is associated with a surge in costs such as information seeking and use (Byström and Järvelin, 1995). Yet, when comparing and contrasting the two levels of analysis emphasized in this paper, we argue that the costs of complexity dominate in the configurational domain whereas the benefits of complexity prevail on the level of tasks. Future research should thus continue investigating how and under what conditions complexity can increase revenue and eventually promote competitiveness, and how different types of complexity may yield different results.

These results have broader implications for management and strategy research. First, our findings shed light on the trade-off between managing coordination costs and meeting client expectations through the set-up of complex operations. On the one hand, we find that building configuration complexity, e.g. through diversification, may facilitate access to markets or improve existing client relationships, but these benefits are potentially undermined by the 
coordination costs involved in setting up such operations. Interestingly, while we do find that a higher degree of commoditization of distributed processes may lower such costs (see e.g. Davenport, 2005), this may also generate another dilemma: the more commoditized the processes are, the easier others can imitate them. This is a dilemma global service providers are currently facing: while many have responded to the demand of clients for global delivery networks (see e.g. Manning et al., 2015), their ability to actually differentiate from competitors is limited, since many peers have established very similar systems. It is thus important to realize that managing distributed operations poses a strategic dilemma that cannot be easily resolved. Future research should thus investigate more systematically how firms deal with the dilemma of the coordination benefits of commoditization and the threat of imitation.

On the other hand, we also argue that task complexity is only beneficial for client-serving firms if the task can be completed without significant client-specific investments that would increase costs and lower information asymmetry. Again, this poses an interesting dilemma. Prior research shows that while providing sophisticated services may indeed drive revenue, longerterm profitability is more a function of how likely clients are willing to renew contracts and develop enduring relationships with suppliers (Larsen and Lyngsie, 2016). This, in turn, is affected by the willingness of suppliers to make client-specific investments (see e.g. Manning et al., 2011; Luo et al., 2013). However, making such investments may also lower the ability of providers to generate economies of scale and exploit capabilities across client relationships (Kang et al., 2009). So, even at the task level, our findings point to more systematic performance dilemmas firms may face when offering complex and sophisticated products and services. Future research should hence explore how firms balance the benefits of retaining information asymmetry while building long-term relationships with their clients. 
Our results also carry important managerial and practical implications. Our article shows that firms, especially in business-to-business sectors, may turn configuration complexity into a value proposition for clients, which would potentially allow them to delegate part of the coordination costs and generate more revenue. For example, global consulting firms are particularly good at linking their global presence to their ability of simultaneously serving multiple operations of globally distributed clients. Their global presence may be turned into a rather intangible asset and capability that allows them to not only charge clients higher rates, but also make them invest into systems that suppliers have built up across their own network already. High-end software providers, such as SAP, would be another good example of such a strategy. Similarly, Manning et al. (2015) find that global service providers are more likely to build global delivery networks if their clients demand - and select providers based on - high speed of service delivery. Turning configuration complexity into a more client-oriented asset may also solve the dilemma posed by commoditization. The more clients are willing to pay for globally integrated supplier structures, the less pressure on margins providers face and the less they are dependent on limiting global expansion to highly competitive operations.

This study also has some notable limitations that future research should seek to address. First, research should strive to identify more sophisticated and accurate measures of task and configuration complexity. While we have relied on previous literature in measuring these constructs, a central component of our argument is that these types of complexity create coordination costs and information asymmetry, respectively. Unfortunately, given the nature of our cross-sectional data we are not able to directly measure these mechanisms. Also, the use of single-items for measures, such as task complexity and commoditization, is a limitation of our empirical strategy. Thus, besides the immediate limitations related to our proxies, the research 
design makes it difficult to appropriately detect problems of endogeneity. Future studies should therefore seek to create more robust, multi-item constructs of the variables underlying the hypothesized relationships presented in this article. Another fruitful avenue for further research would be to explore the multilevel nature of the issue as complexity affects many levels in the organization. Specifically, while we have emphasized how task and configuration complexity affects performance differently, it may also be that these types of complexity impact different levels of the firm differently. Accordingly, future research could look into the nature of different the firm level effects. For example, research could investigate the amount of complexity occurring at different levels of the firms; how different firm-level variables may interact; and eventually how this alters the effects of complexity on performance. Relatedly, we have only discussed and measured performance in terms of a perceptual measure of profit margins. Although this is not an uncommon measurement of firm performance, and in particular in highly innovative, competitive and fast-changing industries, there are reasons to question this measure. For example, service quality (Elia et al., 2014) or sales growth (Lahiri and Kedia, 2009) may be equally important performance measures in the service provider industry. We therefore encourage future research to strive for alternative and objective measures when exploring the performance consequences of complexity.

In conclusion, we have presented findings that put more weight on the performance mechanisms of complexity. While we have emphasized the theoretical implications of this focus, we also argue that our findings contribute to a more nuanced understanding of performance conditions in the service provider industry. Whereas many studies in the offshoring and outsourcing domain have taken a client view by emphasizing their need to save costs and mitigate risks associated with providers (Luo et al. 2013; Narayahan et al., 2011), we take a 
provider's perspective. In particular, we emphasize key tensions facing providers between the need to increase the scope and distribution of operations along with client-specific investments to attract clients, which puts pressure on margins, and the possibility to commoditize processes, yet also focus on more complex tasks to generate revenue opportunities (Sako, 2006). Importantly, we demonstrate how coordination costs may function as a crucial performance determinant in an industry characterized by a rich variety of services, firms, and highly innovative, competitive and fast-changing markets. 


\section{REFERENCES}

Aiken, L. S. and S. G. West (1991). Multiple regression: Testing and interpreting interactions. Newbury Park: Sage.

Akerlof, G.A. (1970). "The market for "lemons": Quality uncertainty and the market mechanism', Quarterly Journal of Economics, 84(3), pp. 488-500.

Albert, D., M. Kreutzer and C. Lechner. (2015). 'Resolving the paradox of interdependency and strategic renewal in activity systems', Academy of Management Review, 40(2), pp. 210-234.

Allen, T.J. (1977). Managing the Flow of Technology. MIT Press, Cambridge, MA.

Anderson, P. (1999). 'Complexity theory and organization science', Organization Science, 10(3), pp. 216-232.

Athreye, S.S. (2005). 'The Indian software industry and its evolving service capability', Industrial and Corporate Change, 14(3), pp. 393-418.

Baldwin, C.Y. and K.B. Clark (2000). Design rules. vol. 1 - The power of modularity. The MIT Press, Cambridge, Mass.

Blau, J.R. and W. McKinley (1979). 'Idea, complexity, and innovation', Administrative Science Quarterly, 24(2), pp. 200-219.

Brusoni, S. (2005). 'The limits to specialization: Problem solving and coordination in Modular Networks', Organization Studies, 26(12), pp. 1885-1907.

Byström, K. and K. Järvelin (1995). 'Task complexity affects information seeking and use', Information Processing \& Management, 31(2), pp. 191-213.

Campbell, D.J. (1988). 'Task complexity: a review and analysis', Academy of Management Review, 13(1), pp. 40-52.

Crozier, M. and E. Friedberg (1980). Actors and systems: The politics of collective action. Chicago: University of Chicago Press.

Damanpour, F. (1996). 'Organizational complexity and innovation: developing and testing multiple contingencies', Management Science, 42(5), pp. 693-716.

Davenport, T.H. (2005). 'The coming commoditization of processes', Harvard Business Review, 83(6), pp. 100-108.

Dougherty, D. (2004). 'Organizing practices in services: capturing practice-based knowledge for innovation', Strategic Organization, 2(1), pp. 35-64.

Dossani, R. and M. Kenney (2003). 'Lift and shift': moving the back office to India', Information Technologies \& International Development, 1(2), pp. 21-37.

Elia, S., F.Caniato, D.Luzzini, and L. Piscitello (2014). 'Governance choice in global sourcing of services: the impact on service quality and cost saving performance', Global Strategy Journal, 4(3), pp. 181-199.

Ellram, L.M., W.L. Tate and C. Billington (2008). 'Offshore outsourcing of professional services: A transaction cost economics perspective', Journal of Operations Management, 26, pp. $148-163$.

Ethiraj, S.K. and D. Levinthal (2004). 'Bounded rationality and the search for organizational architecture: an evolutionary perspective on the design of organizations and their evolvability', Administrative Science Quarterly, 49(3), pp. 404-437.

Ethiraj, S.K., P. Kale, M.S. Krishnan and J.V. Singh (2005). 'Where do capabilities come from and how do they matter? A study in the software industry', Strategic Management Journal, 26, pp. 25-45.

Galbraith, J.R. (1973). Designing Complex Organizations. Reading, Mass.: Addison Wesley. 
Gospel, H. and M. Sako (2010). 'The unbundling of corporate functions: the evolution of shared services and outsourcing of human resource management', Industrial and Corporate Change, 19(5), pp. 1367-1396.

Gulati, R. and H. Singh (1998). 'The architecture of cooperation: Managing coordination costs and appropriation concerns in strategic alliances', Administrative Science Quarterly, 43(4), pp. 781-814.

Hannan, M.T. and J. Freeman (1984). 'Structural inertia and organizational change', American Sociological Review, 49(2), pp. 149-164.

Hofmann, D.A. and M.B. Gavin (1998). 'Centering Decisions in Hierarchical Linear Models:

Implications for Research in Organizations', Journal of Management, 24(5), pp. 623-641.

Houchin, K., and D. MacLean (2005). 'Complexity theory and strategic change: An empirically informed critique', British Journal of Management, 16(2), pp. 149-166.

Husted, B.W. (2007). 'Agency, information, and the structure of moral problems in business', Organization Studies, 28(2), pp. 177-195

Hærem, T., B.T. Pentland and K.D. Miller (2015). 'Task complexity: Extending a core concept', Academy of Management Review, 40(3), pp. 446-460.

Jensen, M. and W. Meckling (1976). 'Theory of the firm: Managerial behavior, agency costs, and ownership structure', Journal of Financial Economics, 3, pp. 303-360.

Jones, O. (2000). 'Innovation management as a post-modern phenomenon: the outsourcing of pharmaceutical R\&D’, British Journal of Management, 11(4), pp. 341-356.

Kumar, K., P.C. van Fenema and M.A. von Glinow (2009). 'Offshoring and the global distribution of work: implications for task interdependence theory and practice', Journal of International Business Studies, 40(4), pp. 642-667.

Lahiri, S. and B.L. Kedia (2009). 'The effects of internal resources and partnership quality on firm performance: An examination of Indian BPO providers', Journal of International Management, 15(2), pp. 209-224.

Lahiri, S., B.L. Kedia and D. Mukherjee (2012). 'The impact of management capability on the resource-performance linkage: examining Indian outsourcing providers', Journal of World Business, 47, pp. 145-155.

Larsen, M. M., \& Lyngsie, J. (2016). Ambiguous adaptation: The effect of contract duration and investments in relational mechanisms on premature relationship termination. Long Range Planning.

Larsen, M.M., S. Manning and T. Pedersen (2013). 'Uncovering the hidden costs of offshoring: The interplay of complexity, organizational design, and experience', Strategic Management Journal, 34(5), pp. 533-552.

Levinthal, D.A. (1997). 'Adaptation on rugged landscapes', Management Science, 43(7), pp. 934-950.

Lewin, A.Y., S. Massini and C. Peeters (2009). 'Why are companies offshoring innovation? The emerging global race for talent', Journal of International Business Studies, 40 (8), pp. 14061406.

Lindell, M. K. and D. J. Whitney (2001). 'Accounting for common method variance in crosssectional research designs', Journal of Applied Psychology, 86(1), pp. 114.

Lippman, S.A. and R.P. Rumelt (1982). 'Uncertain Imitability: An Analysis of Interfirm Differences in Efficiency under Competition', The Bell Journal of Economics, 13(2), pp. 418438. 
Luo, Y., S. Wang, V. Jayaraman and Q. Zheng (2013). 'Governing business process offshoring: Properties, processes, and preferred modes', Journal of World Business, 48(3), pp. 407-419.

Løwendahl, B. R. and Ø. Revang, (1998). 'Challenges to existing strategy theory in a postindustrial society', Strategic Management Journal 19(8), pp. 755-773.

Manning, S., Hutzschenreuter, T., Strathmann, A. (2013). 'Emerging Capability or Continuous Challenge? Relocating Knowledge Work and Managing Process Interfaces'. Industrial and Corporate Change, 22 (5), pp. 1159-1193.

Manning, S., M.M. Larsen and P. Bharati (2015). 'Global delivery models: The role of talent, speed and time zones in the global outsourcing industry', Journal of International Business Studies, 46(7), pp. 850-877.

Manning, S., A.Y. Lewin and M. Schuerch (2011). 'The stability of offshore outsourcing relationships: The role of relation specificity and client control', Management International Review, 51(3), pp. 381-406.

Manning, S., S. Massini and A.Y. Lewin (2008). 'A dynamic perspective on next-generation offshoring: the global sourcing of science and engineering talent', Academy of Management Perspectives, 22(3), pp. 35-54.

Massini, S., N. Perm-Ajchariyawong and A.Y. Lewin (2010). 'Role of corporate-wide offshoring strategy on offshoring drivers, risks and performance', Industry \& Innovation, 17(4), pp. 337371.

Miller, C. C., Washburn, N. T., \& Glick, W. H. (2013). 'Perspective- the myth of firm performance'. Organization Science, 24(3), 948-964.

Moldoveanu, M.C. and R.M. Bauer (2004). 'On the relationship between organizational complexity and organizational structuration', Organization Science, 15(1), pp. 98-118.

Murmann, P.A. (1994). 'Expected development time reductions in the German mechanical engineering industry', Journal of Product Innovation Management, 11(3), pp. 236-252.

Narayahan, S., V. Jayaraman, Y. Luo and J. Swaminathan (2011). 'The antecedents of process integration in business process outsourcing and its effect on firm performance', Journal of Operations Management, 29, pp. 3-16.

Nayyar, P.R. (1993). 'Performance effects of information asymmetry and economics of scope in diversified service firms', Academy of Management Journal, 36(1), pp. 28-57.

Niosi, J. (2011). Complexity and path dependence in biotechnology innovation systems. Industrial and Corporate Change, 20(6), pp. 1795-1826.

Park, S.H. and G.R. Ungson (2001). 'Interfirm rivalry and managerial complexity: A conceptual framework of alliance failure', Organization Science, 12(1), pp. 37-53.

Podsakoff, P.M. and D.W. Organ (1986). 'Self-reports in organizational research: problems and prospects', Journal of Management, 12, pp. 69-82.

Podsakoff, P.M., S.B. MacKenzie and N.P. Podsakoff (2003). 'Common method bias in behavioral research: A critical review of the literature and recommended remedies', Journal of Applied Psychology, 88, pp. 879-903.

Porter, M.E. and N. Siggelkow (2008). 'Contextual Interactions within Activity Systems and Sustainability of Competitive Advantage', Academy of Management Perspectives, 22(2), pp. 34-56.

Powell, T.C., D. Lovallo and C. Caringal (2006). 'Causal ambiguity, management perception, and firm performance', Academy of Management Review, 31(1), pp. 175-196.

Rawley, E. (2010). 'Diversification, coordination costs, and organizational rigidity: Evidence from microdata', Strategic Management Journal, 31(8), pp. 873-891. 
Reed, R. and R. DeFillippi (1990). 'Causal ambiguity, barriers to imitation, and sustainable competitive advantage', Academy of Management Review, 15, pp. 88-102.

Rivkin, J.W. (2000). 'Imitation of complex strategies', Management Science, 46(6), pp. 824-844. Rivkin, J.W. (2001). 'Reproducing knowledge: Replication without imitation at moderate complexity', Organization Science, 12, pp. $274-293$.

Robson, M.J., C.S. Katsikeas and D.C. Bello (2008). 'Drivers and performance outcomes of trust in international strategic alliances: The role of organizational complexity', Organization Science, 19(4), pp. 647-665.

Sako, M. (2006). 'Outsourcing and offshoring: Implications for productivity of business services', Oxford Review of Economic Policy, 22(4), pp. 499-512.

Siemsen, E., A. Roth and P. Oliveira (2010). 'Common method bias in regression models with linear, quadratic, and interaction effects', Organizational Research Methods, 13, pp. 456-476.

Siggelkow, N. (2001). 'Change in the Presence of Fit: The Rise, the Fall, and the Renaissance of Liz Claiborne', Academy of Management Journal, 44(4), pp. 838-857.

Siggelkow N. and J.W. Rivkin (2005). 'Speed and Search: Designing Organizations for Turbulence and Complexity', Organization Science, 16, pp. 101-122.

Simon, H.A. (1962). 'The architecture of complexity', Proceedings of the American Philosophical Society, 106, pp. 467-482.

Simon, H. A. (2002). Near decomposability and the speed of evolution. Industrial and corporate change, 11(3), pp. 587-599.

Srikanth, K. and P. Puranam (2011). 'Integrating distributed work: comparing task design, communication, and tacit coordination mechanisms', Strategic Management Journal, 32(8), pp. 849-875.

Sturdy, A. (1997). The consultancy process - an insecure business? Journal of Management Studies, 34(3), 389-413.

Tanriverdi, H., P. Konana and L. Ge (2007). 'The choice of sourcing mechanisms for business processes', Information System Research, 18(3), pp. 280-299.

Teece, D.J. 1980. 'Economies of scope and the scope of the enterprise', Journal of Economic Behavior and Organization, 1(3), pp. 223-247.

Thompson, J.D. (1967). Organizations in Action: Social Science Bases of Administrative Theory. McGraw-Hill: New York.

Tushman, M.L. and D.A. Nadler (1978). 'Information processing as an integrating concept in organizational design', Academy of Management Review, 3(3), pp. 613-624.

Von Hippel, E. (1994). 'Sticky information' and the locus of problem solving: Implications for Innovation', Management Science, 4(40), pp. 429-439.

Weigelt, C., and D.J. Miller (2013). 'Implications of internal organization structure for firm boundaries', Strategic Management Journal, 34(12), pp. 1411-1434.

Williamson, O.E. (1975). Markets and Hierarchies. Free Press: New York.

Williamson, O.E. (1985). The Economic Institutions of Capitalism. Free Press: New York.

Wood, R.E. (1986). 'Task complexity: definition of the construct', Organizational Behavior and Human Decision Processes, 37, pp. 60-82.

Zhou, Y.M. (2011). 'Synergy, coordination costs, and diversification choices', Strategic Management Journal, 32(6), pp. 624-639.

Zhou, Y.M. (2013). 'Designing for complexity: Using divisions and hierarchy to manage complex tasks', Organization Science, 24(2), pp. 339-355. 
Figure 1: Relation between configuration complexity and process commoditization

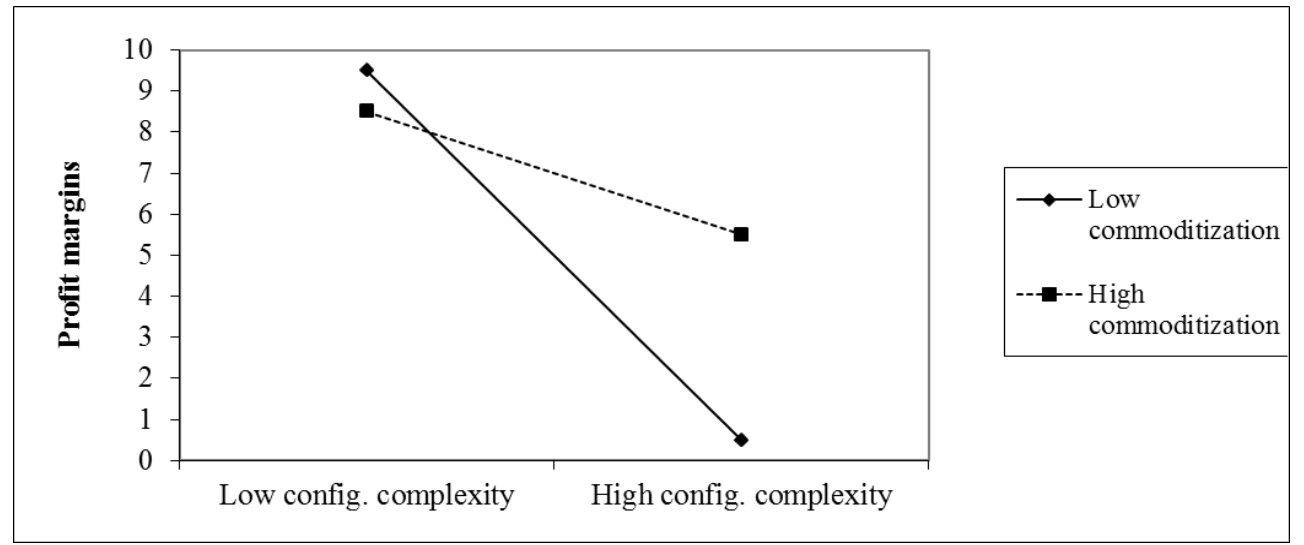

Figure 2: Relation between task complexity and client-specific investments

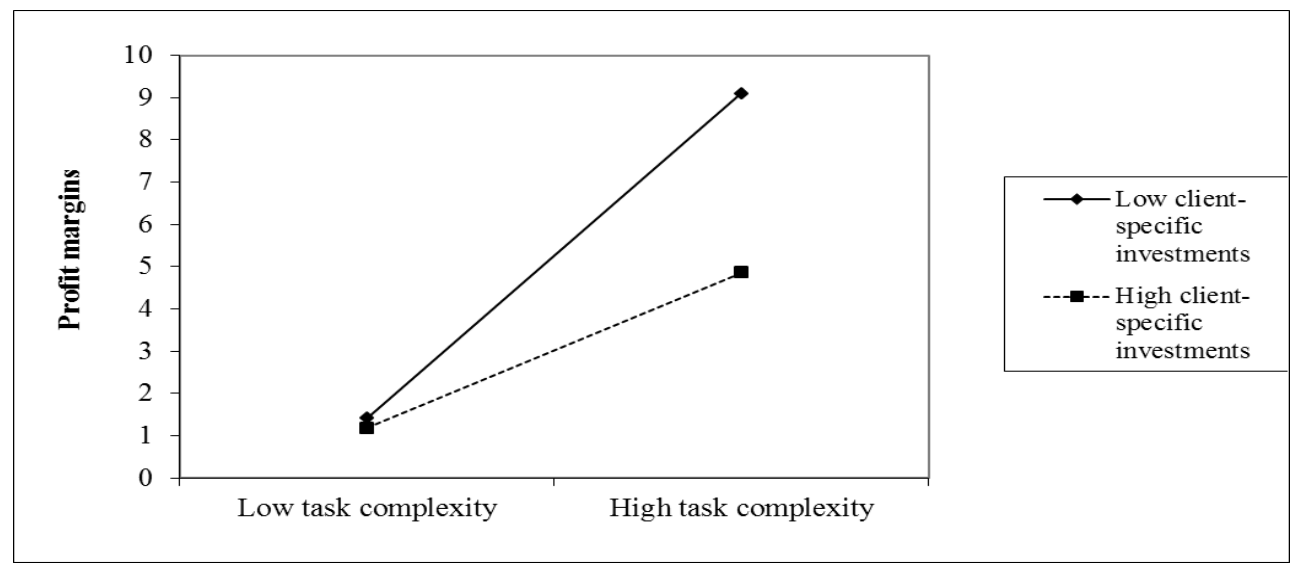


Table 1: Correlation matrix $(n=432)^{*}$

\begin{tabular}{|c|c|c|c|c|c|c|c|c|c|c|c|c|c|c|c|c|c|c|c|c|c|c|c|c|c|c|c|c|c|}
\hline & 1 & 2 & 3 & 4 & 5 & 6 & 7 & 8 & 9 & 10 & 11 & 12 & 13 & 14 & 15 & 16 & 17 & 18 & 19 & 20 & 21 & 22 & 23 & 24 & 25 & 26 & 27 & 28 & 29 \\
\hline 1) Profit margins & 1 & & & & & & & & & & & & & & & & & & & & & & & & & & & & \\
\hline 2) Configuration complexity & -0.01 & 1 & & & & & & & & & & & & & & & & & & & & & & & & & & & \\
\hline 3) Task complexity & 0.16 & 0.03 & 1 & & & & & & & & & & & & & & & & & & & & & & & & & & \\
\hline 4) Commoditization & 0.03 & -0.01 & -0.24 & 1 & & & & & & & & & & & & & & & & & & & & & & & & & \\
\hline 5) Client-specific investment & -0.01 & 0.01 & 0.11 & -0.04 & 1 & & & & & & & & & & & & & & & & & & & & & & & & \\
\hline 6) Provider experience & -0.14 & -0.06 & 0.06 & 0.04 & 0.03 & 1 & & & & & & & & & & & & & & & & & & & & & & & \\
\hline 7) Number of services & -0.15 & 0.09 & -0.02 & -0.11 & 0.12 & -0.01 & 1 & & & & & & & & & & & & & & & & & & & & & & \\
\hline 8) Duration of deals & -0.13 & 0.06 & 0.03 & 0.02 & 0.14 & 0.29 & 0.06 & 1 & & & & & & & & & & & & & & & & & & & & & \\
\hline 9) Specification of contracts & -0.03 & -0.01 & 0.2 & -0.09 & 0.11 & 0.06 & 0.11 & 0.2 & 1 & & & & & & & & & & & & & & & & & & & & \\
\hline 10) Competition & 0.11 & 0.06 & 0.11 & -0.23 & -0.01 & -0.02 & -0.03 & -0.06 & 0.07 & 1 & & & & & & & & & & & & & & & & & & & \\
\hline 11) Long-term relationships & -0.14 & 0.01 & 0.12 & 0.01 & 0.15 & 0.34 & 0.22 & 0.3 & 0.34 & -0.02 & 1 & & & & & & & & & & & & & & & & & & \\
\hline 12) Use of suncontractor & 0.12 & 0.03 & -0.08 & 0.03 & -0.2 & 0.04 & -0.16 & -0.11 & -0.05 & 0.05 & -0.15 & 1 & & & & & & & & & & & & & & & & & \\
\hline 13) Innovation as a driver & 0.08 & -0.02 & 0.28 & -0.01 & 0.05 & 0.06 & -0.1 & 0.07 & 0.16 & 0.08 & 0.11 & 0.04 & 1 & & & & & & & & & & & & & & & & \\
\hline 14) $R \& D$ & 0.08 & 0.01 & 0.2 & -0.08 & -0.04 & 0.01 & 0.05 & -0.06 & -0.01 & -0.03 & -0.03 & -0.01 & ${ } 0.06$ & 1 & & & & & & & & & & & & & & & \\
\hline 15) Call Center & -0.06 & -0.12 & -0.21 & 0.19 & 0.1 & -0.01 & 0.06 & 0.09 & 0.04 & -0.34 & 0.04 & -0.1 & -0.09 & -0.08 & 1 & & & & & & & & & & & & & & \\
\hline 16) Engineering Services & -0.03 & -0.02 & 0.08 & -0.01 & -0.01 & 0.08 & 0.03 & -0.07 & -0.07 & -0.18 & -0.03 & -0.04 & 0.05 & -0.06 & -0.08 & 1 & & & & & & & & & & & & & \\
\hline 17) Finance/accounting & -0.03 & 0.07 & -0.11 & -0.08 & 0.05 & -0.02 & 0.01 & 0.06 & 0.07 & -0.08 & 0.03 & -0.07 & -0.01 & -0.07 & -0.09 & -0.07 & 1 & & & & & & & & & & & & \\
\hline 18) Human Resources & 0.04 & 0.02 & -0.13 & -0.01 & 0.01 & -0.05 & 0.09 & 0.01 & 0.15 & 0.32 & 0.03 & -0.06 & -0.02 & -0.06 & -0.08 & -0.06 & -0.07 & 1 & & & & & & & & & & & \\
\hline 19) IT infrastructure & -0.03 & 0.04 & -0.01 & 0.15 & -0.07 & 0.04 & -0.09 & 0.02 & -0.08 & -0.37 & -0.02 & 0.06 & -0.04 & -0.12 & -0.16 & -0.13 & -0.14 & -0.13 & 1 & & & & & & & & & & \\
\hline 20) Knowledge Services & 0.06 & 0.03 & 0.14 & -0.16 & 0.05 & 0.03 & 0.13 & -0.04 & 0.1 & 0.22 & 0.08 & 0.04 & 0.04 & -0.05 & -0.07 & -0.05 & -0.06 & -0.05 & -0.11 & 1 & & & & & & & & & \\
\hline 21) Legal Services & 0.01 & -0.01 & -0.04 & -0.08 & 0.06 & -0.03 & -0.01 & -0.01 & 0.02 & 0.17 & -0.05 & 0.05 & 0.02 & -0.03 & -0.04 & -0.03 & -0.03 & -0.03 & -0.07 & -0.03 & 1 & & & & & & & & \\
\hline 22) Marketing and Sales & 0.04 & -0.01 & -0.11 & -0.06 & 0.06 & -0.05 & 0.01 & 0.01 & -0.02 & 0.20 & 0.02 & -0.01 & 0.02 & -0.05 & -0.07 & -0.06 & -0.06 & -0.06 & -0.12 & -0.05 & -0.03 & 1 & & & & & & & \\
\hline 23) Procurement & -0.11 & -0.01 & -0.09 & -0.04 & -0.08 & -0.06 & 0.04 & 0.02 & -0.01 & -0.11 & 0.02 & 0.11 & -0.03 & -0.05 & -0.06 & -0.05 & -0.05 & -0.05 & -0.1 & -0.04 & -0.03 & -0.04 & 1 & & & & & & \\
\hline 24) Design & 0.04 & 0.01 & 0.07 & -0.04 & -0.04 & -0.01 & 0.07 & 0.01 & -0.01 & 0.01 & 0.03 & 0.04 & -0.02 & -0.05 & -0.07 & -0.06 & -0.06 & -0.06 & -0.12 & -0.05 & -0.03 & -0.05 & -0.04 & 1 & & & & & \\
\hline 25) Soft ware Development & -0.01 & -0.04 & 0.15 & 0.08 & -0.01 & -0.03 & -0.14 & -0.07 & -0.09 & 0.32 & -0.96 & -0.05 & 0.02 & -0.11 & -0.15 & -0.12 & -0.12 & -0.12 & -0.24 & -0.1 & -0.06 & -0.11 & -0.09 & -0.1 & 1 & & & & \\
\hline 26) HQ-Latin America & -0.07 & 0.01 & -0.03 & 0.05 & -0.08 & -0.02 & 0.01 & 0.13 & 0.01 & -0.06 & -0.02 & -0.06 & -0.15 & -0.04 & 0.07 & -0.04 & -0.05 & -0.01 & 0.03 & -0.06 & -0.04 & -0.03 & 0.07 & 0.01 & -0.01 & 1 & & & \\
\hline 27) HQ-North America & 0.19 & 0.04 & 0.1 & -0.07 & 0.08 & 0.04 & 0.05 & 0.11 & 0.08 & 0.06 & 0.04 & -0.01 & 0.01 & -0.05 & -0.01 & -0.02 & 0.06 & -0.01 & -0.07 & 0.01 & 0.15 & 0.04 & 0.01 & 0.04 & 0.01 & -0.2 & 1 & & \\
\hline 28) HQ-Europe & -0.07 & -0.02 & -0.03 & 0.07 & -0.1 & -0.01 & -0.21 & -0.11 & -0.19 & 0.04 & -0.03 & 0.12 & 0.02 & -0.01 & -0.09 & -0.01 & -0.07 & -0.04 & 0.07 & 0.01 & -0.07 & 0.07 & 0.05 & -0.07 & 0.04 & -0.2 & -0.35 & 1 & \\
\hline 29) HQ-Asia & -0.02 & 0.03 & 0.01 & 0.02 & 0.07 & -0.08 & 0.18 & -0.07 & 0.09 & -0.06 & 0.02 & -0.03 & 0.09 & 0.08 & 0.04 & 0.07 & 0.01 & 0.04 & -0.02 & 0.01 & -0.04 & -0.03 & -0.08 & 0.06 & -0.06 & -0.2 & -0.44 & -0.34 & 1 \\
\hline Mean & 26 & -0.01 & 3.6 & 3.1 & 3.3 & 9.17 & 3.75 & 2.26 & 3.29 & 56.3 & 35.1 & 0.25 & 3.23 & 0.06 & 0.09 & 0.06 & 0.07 & 0.06 & 0.21 & 0.04 & 0.02 & 0.05 & 0.04 & 0.05 & 0.18 & 0.08 & 0.31 & 0.21 & 0.30 \\
\hline Standard deviation & 18.6 & 0.35 & 1.02 & 1.04 & 1.13 & 8.49 & 2.2 & 2.73 & 1.03 & 27.7 & 32.5 & 0.43 & 1.07 & 0.23 & 0.29 & 0.24 & 0.25 & 0.24 & 0.4 & 0.2 & 0.13 & 0.22 & 0.19 & 0.22 & 0.38 & 0.28 & 0.46 & 0.41 & 0.46 \\
\hline Min. value & 0 & -4.54 & 1 & 1 & 1 & 0 & 1 & 0 & 1 & 9.63 & 0 & 0 & 1 & 0 & 0 & 0 & 0 & 0 & 0 & 0 & 0 & 0 & 0 & 0 & 0 & 0 & 0 & 0 & 0 \\
\hline Max. value & 100 & 2.15 & 5 & 5 & 5 & 85 & 10 & 37 & 5 & 100 & 100 & 1 & 5 & 1 & 1 & 1 & 1 & 1 & 1 & 1 & 1 & 1 & 1 & 1 & 1 & 1 & 1 & 1 & 1 \\
\hline
\end{tabular}

* all values above $|0.09|$ are significant at 5\%-level of significance 
Table 2: Hierarchical Linear Modelling $(n=432) *$ with profit margins as the DV (standard errors in parentheses and VIF-values in Italics)

\begin{tabular}{|c|c|c|c|c|c|}
\hline & Model 1 & Model 2 & Model 3 & Model 4 & Model 5 \\
\hline Configuration complexity & & & $\begin{array}{c}-0.01 \\
(0.03)-1.76\end{array}$ & $\begin{array}{c}-0.10^{*} \\
(0.04)-1.77\end{array}$ & $\begin{array}{c}-0.19 * * \\
(0.07)-10.69\end{array}$ \\
\hline Task complexity & & $\begin{array}{c}2.63 * * \\
(0.62)-1.55\end{array}$ & & $\begin{array}{c}2.64 * * * \\
(0.63)-1.55\end{array}$ & $\begin{array}{c}2.84 * * * \\
(0.63)-9.99\end{array}$ \\
\hline Commoditization & & $\begin{array}{c}0.15 \\
(0.58)-1.25\end{array}$ & $\begin{array}{c}0.82 \\
(0.58)-1.18\end{array}$ & $\begin{array}{c}0.15 \\
(0.58)-1.25\end{array}$ & $\begin{array}{c}0.73 \\
(0.65)-4.64\end{array}$ \\
\hline \multirow{2}{*}{$\begin{array}{l}\text { Client-specific investment } \\
\text { Configuration complexity } * \text { Commoditization }\end{array}$} & & $\begin{array}{c}-0.61 \\
(0.57)-1.14 \\
\end{array}$ & $\begin{array}{c}-0.50 \\
(0.59)-1.18 \\
\end{array}$ & $\begin{array}{c}-0.57 \\
(0.59)-1.19 \\
\end{array}$ & $\begin{array}{c}-0.72 \\
(0.65)-14.56 \\
\end{array}$ \\
\hline & & & & & $\begin{array}{c}0.69 * * \\
(0.30)-10.10\end{array}$ \\
\hline Task complexity $*$ Client-specific investment & & & & & $\begin{array}{c}-0.25^{*} \\
(0.12)-15.60\end{array}$ \\
\hline \multirow{2}{*}{$\begin{array}{l}\text { Control variables } \\
\text { Years of experience with service }\end{array}$} & & & & & \\
\hline & $\begin{array}{c}0.06 \\
(0.08)-1.28 \\
\end{array}$ & $\begin{array}{c}0.05 \\
(0.08)-1.29 \\
\end{array}$ & $\begin{array}{c}0.06 \\
(0.08)-1.31 \\
\end{array}$ & $\begin{array}{c}0.05 \\
(0.08)-1.31 \\
\end{array}$ & $\begin{array}{c}0.06 \\
(0.08)-1.33 \\
\end{array}$ \\
\hline Number of services & $\begin{array}{c}0.43 \\
(0.72)-1.23\end{array}$ & $\begin{array}{c}0.36 \\
(0.71)-1.24\end{array}$ & $\begin{array}{c}0.41 \\
(0.72)-1.26\end{array}$ & $\begin{array}{c}0.35 \\
(0.71)-1.26\end{array}$ & $\begin{array}{c}0.37 \\
(0.71)-1.27\end{array}$ \\
\hline Average duration of deals & $\begin{array}{c}-0.06 \\
(0.25)-1.26 \\
\end{array}$ & $\begin{array}{c}-0.07 \\
(0.25)-1.27 \\
\end{array}$ & $\begin{array}{c}-0.06 \\
(0.25)-1.27 \\
\end{array}$ & $\begin{array}{c}-0.07 \\
(0.25)-1.27 \\
\end{array}$ & $\begin{array}{c}-0.04 \\
(0.25)-1.28 \\
\end{array}$ \\
\hline Specification of contracts & $\begin{array}{c}-0.06 \\
(0.59)-1.27\end{array}$ & $\begin{array}{c}-0.12 \\
(0.57)-1.32\end{array}$ & $\begin{array}{c}-0.07 \\
(0.59)-1.28\end{array}$ & $\begin{array}{c}-0.11 \\
(0.57)-1.33\end{array}$ & $\begin{array}{c}-0.02 \\
(0.57)-1.33\end{array}$ \\
\hline Competition & $\begin{array}{c}-0.12 \\
(0.07)-8.75\end{array}$ & $\begin{array}{c}-0.16 \\
(0.07)-8.71\end{array}$ & $\begin{array}{c}-0.11 \\
(0.08)-9.24\end{array}$ & $\begin{array}{c}-0.17 * \\
(0.08)-9.78\end{array}$ & $\begin{array}{c}-0.20 * * \\
(0.08)-10.12\end{array}$ \\
\hline Share of relationships lasting 5 years or more & $\begin{array}{c}-0.06 \\
(0.04)-1.44\end{array}$ & $\begin{array}{c}-0.06 \\
(0.04)-1.45\end{array}$ & $\begin{array}{c}-0.06 \\
(0.04)-1.45\end{array}$ & $\begin{array}{c}-0.06 \\
(0.04)-1.45\end{array}$ & $\begin{array}{c}-0.06 \\
(0.04)-1.46\end{array}$ \\
\hline Use of subcontractor & $\begin{array}{c}2.48 \\
(1.41)-1.13 \\
\end{array}$ & $\begin{array}{c}3.21^{*} \\
(1.39)-1.18 \\
\end{array}$ & $\begin{array}{c}2.75^{*} \\
(1.42)-1.17 \\
\end{array}$ & $\begin{array}{c}3.25^{*} \\
(1.40)-1.18 \\
\end{array}$ & $\begin{array}{c}3.59 * \\
(1.40)-1.19 \\
\end{array}$ \\
\hline \multirow[b]{2}{*}{ Area of service (12 dummies) } & $\begin{array}{c}0.34 \\
(0.65)-1.11\end{array}$ & $\begin{array}{c}0.29 \\
(0.65)-1.18\end{array}$ & $\begin{array}{c}0.31 \\
(0.65)-1.14\end{array}$ & $\begin{array}{c}0.27 \\
(0.65)-1.21\end{array}$ & $\begin{array}{c}0.26 \\
(0.65)-1.21\end{array}$ \\
\hline & Yes & Yes & Yes & Yes & Yes \\
\hline Region of headquarter (4 dummies) & Yes & Yes & Yes & Yes & Yes \\
\hline \multirow{2}{*}{$\begin{array}{c}\text { Intercept } \\
\text { Firm-effects (Level } 1 \text { - Intercept) }\end{array}$} & $\begin{array}{c}29.8^{* * * *} \\
(1.48)\end{array}$ & $\begin{array}{c}26.8^{* * * *} \\
(1.47)\end{array}$ & $\begin{array}{c}26.8^{* * * *} \\
(1.48)\end{array}$ & $\begin{array}{c}26.8^{* * *} \\
(1.47)\end{array}$ & $\begin{array}{l}26.9^{* * * *} \\
(1.47)\end{array}$ \\
\hline & $\begin{array}{c}275.3 * * * \\
(31.6)\end{array}$ & $\begin{array}{c}273.6^{* * * *} \\
(31.2)\end{array}$ & $\begin{array}{l}276.6^{* * * *} \\
(31.7)\end{array}$ & $\begin{array}{l}272.1 * * * \\
(31.2)\end{array}$ & $\begin{array}{c}271.6^{* * *} \\
(31.1)\end{array}$ \\
\hline $\begin{array}{l}\mathrm{N} \\
\qquad 2 \text { Log Likelihood } \\
\text { Likelihood Ratio test (compared with Model 1) }\end{array}$ & $\begin{array}{c}432 \\
3344.1\end{array}$ & $\begin{array}{c}432 \\
3329.9 \\
14.2(3 \mathrm{df}) * * * \\
\end{array}$ & $\begin{array}{c}432 \\
3342.0 \\
2.1(3 \mathrm{df}) * \\
\end{array}$ & $\begin{array}{c}432 \\
3324.8 \\
19.3(4 \mathrm{df}) * * * \\
\end{array}$ & $\begin{array}{c}432 \\
3320.5 \\
23.6(6 \mathrm{df}) * * * \\
\end{array}$ \\
\hline
\end{tabular}

$*, * *$ and $* * *$ indicates a level of significance of $5 \%, 1 \%$ and $0.1 \%$, respectively. Two-tailed tests, standard errors in parentheses. 
Table 3. Simple slope test for interaction between configuration complexity and commoditization

\begin{tabular}{|l|l|l|l|l|l|}
\hline \multicolumn{1}{|c|}{ Commoditization } & \multicolumn{1}{|c|}{-2 SD } & \multicolumn{1}{|c|}{ Mean } & \multicolumn{1}{|c|}{+ 1 SD } & +2 SD \\
\hline Gradient & -5.05 & -3.43 & -1.97 & -0.94 & -0.15 \\
\hline t-value & -5.97 & -5.57 & -2.23 & -1.56 & -0.10 \\
\hline p-value & 0.00 & 0.00 & 0.03 & 0.08 & 0.92 \\
\hline
\end{tabular}

Table 4. Simple slope test for interaction between task complexity and client-specific investments

\begin{tabular}{|l|l|l|l|l|l|}
\hline \multicolumn{1}{|r|}{ Client-specific investments } & \multicolumn{1}{c|}{-2 SD } & \multicolumn{1}{c|}{ - Mean } & \multicolumn{1}{c|}{+ 1 SD } & +2 SD \\
\hline Gradient & 4.63 & 3.54 & 2.69 & 1.77 & 0.82 \\
\hline $\mathrm{t}$-value & 3.65 & 4.21 & 3.68 & 1.80 & 0.57 \\
\hline p-value & 0.00 & 0.00 & 0.00 & 0.07 & 0.57 \\
\hline
\end{tabular}

